\title{
Produtividade da pimenta-do-reino em função de doses de esterco bovino
}

\author{
Ademar P Oliveira $^{1,2}$; Edna U Alves ${ }^{1}$; Jandiê A Silva ${ }^{1,3}$; Anarlete U Alves ${ }^{1,3}$; Arnaldo Nonato P Oliveira ${ }^{1,4,5}$; \\ Francisco AP Leonardo ${ }^{1,4,5}$; Mácio F Moura ${ }^{1,3}$; Iordam S Cruz ${ }^{1,2,4}$ \\ ${ }^{1}$ UFPB, CCA, C. Postal 02, 58397-000 Areia-PB; ${ }^{2}$ Bolsista CNPq; ${ }^{3}$ Pós-graduação em Agronomia; ${ }^{4}$ Graduação em Agronomia; ${ }^{5}$ Bolsista \\ PIBIC-CNPq; ademar@cca.ufpb.br
}

\begin{abstract}
RESUMO
Embora o estado da Paraíba tenha mostrado certa aptidão para o cultivo da pimenta-do-reino, sendo possível recomendá-la como alternativa de diversificação agrícola, não existe qualquer recomendação de adubação para a espécie. Este trabalho foi realizado na UFPB, em Areia, PB, e teve como objetivo avaliar genótipos de pimenta-do-reino adubados com doses crescentes de esterco bovino, em delineamento experimental de blocos casualizados, com os tratamentos dispostos no esquema fatorial $5 \times 3$, sendo o primeiro fator representado pelas doses de esterco $\left(0 ; 4 ; 8 ; 12\right.$ e $16 \mathrm{~kg}$ planta $\left.{ }^{-1}\right)$ e o segundo pelos genótipos (Bragantina, Iaçará e Cingapura), com quatro repetições. A pimenta-do-reino respondeu positivamente ao emprego de esterco bovino, nas condições edafoclimáticas de Areia. As máximas produções de pimenta verde por planta, dos genótipos Bragantina (1012 g), Iaçará (1269 g) e Cingapura (627 g), foram obtidas com as doses estimadas de 7,3; 8,6 e 7,0 kg planta- ${ }^{-1}$ de esterco bovino, respectivamente. Para produção da pimenta seca, as doses estimadas em 6,5; 8,9 e 7,8 $\mathrm{kg}$ planta $^{-1}$ de esterco bovino foram responsáveis pelas máximas produções correspondendo a 358, 793 e 204 g planta $^{-1}$ para os genótipos Bragantina, Iaçará e Cingapura, respectivamente.
\end{abstract}

Palavras-chave: Piper nigrum, genótipos, adubação orgânica.

\begin{abstract}
Yield of black pepper submitted to different levels of cattle manure

Although Paraíba State, has shown aptitude for black pepper cultivation, being possible to recommend it as an alternative for agricultural diversification in that area, no recommendation for black pepper crop fertilization exists. This research was conducted at the Universidade Federal da Paraíba, in Areia, Paraíba State, Brazil, to evaluate black pepper genotypes submitted to increasing levels of cattle manure. The experimental design was of randomized blocks, with treatments in the factorial $5 \times 3$ scheme. The first factor was represented by cattle manure levels $\left(0 ; 4 ; 8 ; 12\right.$; and $\left.16 \mathrm{~kg} \mathrm{plant}^{-1}\right)$ and the second factor, by the black pepper genotypes (Iaçará, Cingapura and Bragantina), with four replications. Black pepper production increased with the use of cattle manure in environmental conditions. The highest pepper yield per plant of Bragantina (1012 g), Iaçará (1269 g), and Cingapura (627 g) were obtained with 7.3; 8.6; and $7.0 \mathrm{~kg}$ of cattle manure/plant, respectively. The estimated yields of dry pepper were of 6.5; 8.9; and $7.8 \mathrm{~kg} \mathrm{plant}^{-1}$, responding to maximum yields of 358, 793 and 204 g plant $^{-1}$ for Bragantina, Iaçará and Cingapure genotypes, respectively.
\end{abstract}

Keywords: Piper nigrum, genotypes, organic fertilization.

(Recebido para publicação em 23 de maio de 2006; aceito em 11 de setembro de 2007)

$\mathrm{O}$ estado da Paraíba sempre produziu pimenta-do-reino. Entretanto, nos últimos 25 anos, observou-se uma queda de mais de $90 \%$ na produção, decorrente da diminuição da área plantada (1.095 ha em 1975 para menos de 200 ha em 2005) e, principalmente, do decréscimo da produtividade da cultura, cujos valores hoje estimados, não ultrapassam $300 \mathrm{~kg} \mathrm{ha}^{-1}$ de pimenta seca. Estados vizinhos como Rio Grande do Norte e Pernambuco, apresentam rendimentos médios muito superiores, alcançando 3.000 e $1.500 \mathrm{~kg} \mathrm{ha}^{-1}$, respectivamente (IBGE, 2005). A ausência de um programa de fertilização e renovação das áreas de produção, aliada à elevada degenerescência do material genético utilizado na produção de mudas, são fatores implicadores na grave situação atual da pimenta-do-reino na Paraíba.

Embora a pimenta-do-reino seja espécie com habitat natural entre os tró- picos, beneficiando-se de condições de calor e umidade elevada, é possível cultivá-la com sucesso em locais como Campinas e Pindamonhangaba, estado de São Paulo, com temperaturas médias de $20-25^{\circ} \mathrm{C}$ e precipitação pluviométrica média anual de 1.200 a $1.300 \mathrm{~mm}$ (Fornazier Filho, 1989). A região do Brejo Paraibano, maior produtora de pimenta-do-reino da Paraíba, de temperatura média anual entre 23 e $24^{\circ} \mathrm{C}$, pluviosidade média anual de $1.400 \mathrm{~mm}$ e períodos de estiagem de um a três meses (Gondim,1999), reúne condições climáticas favoráveis ao cultivo da pimenta-do-reino.

Esta cultura exige solos com boas características físicas (Fornazier Filho, 1989). Nos estados do Pará e do Espírito Santo, muitas áreas cultivadas com a espécie são representado por Latossolos, de características físicas adequadas, mas com baixa fertilidade natural (Milanez et al., 1987). Na região do Brejo Paraibano também predominam os Latossolos (Gondim, 1999), viabilizado o cultivo comercial da pimenta. No entanto, o solo considerado ideal para a pimenta-do-reino deve apresentar textura arenosa com alto teor de matéria orgânica (Fornazier Filho, 1989). Além dos resultados satisfatórios já obtidos com a adubação mineral da cultura, o aporte de matéria orgânica ao solo tem proporcionado respostas promissoras da pimenta-do-reino (Milanez et al., 1987; Fornazier Filho, 1989).

Dentre as fontes de matéria orgânica recomendadas para a pimenta-do-reino estão os estercos bovino e de aves e torta de oleaginosas, em doses variando de acordo com o teor originalmente presente no solo (Duarte \& Albuquerque, 2005). Nas condições da Região Norte recomenda-se aplicar esterco bovino nas doses de 4,0 kg por cova no transplantio 
das mudas, 4,0 kg no segundo ano e 4,0 kg no terceiro ano de cultivo (Pimentel, 1985). Para as condições do estado do Espírito Santo, recomenda-se o emprego também parcelado, de 10 a $20 \mathrm{~L}$ de esterco bovino por planta (Milanez et al., 1987). Quanto à adubação mineral, a literatura indica seguir orientação laboratorial decorrente da análise química do solo. Para o estado da Paraíba, embora o esterco bovino seja a fonte de matéria orgânica mais prontamente disponível, não se dispõe de qualquer recomendação divulgada para a adubação orgânica de pimenta-do-reino ao longo do tempo (EMATER, 1979).

Existem no Brasil diversas cultivares de pimenta-do-reino de boa aceitação comercial. Entretanto, não há um programa nacional de avaliação que permita indicar cultivares apropriadas a cada região produtora. As cultivares hoje disponíveis estão sendo indiscriminadamente utilizadas, sem levar em conta possíveis diferenças de comportamento para cada ambiente. $\mathrm{Na}$ introdução de genótipos, é importante que se façam avaliações sob as condições edafoclimáticas locais (Peixoto et al., 1993). Estudos tornam-se necessários, pois, regra geral, o produtor utiliza por conta e risco, qualquer cultivar encontrada disponível no mercado, levando-o por vezes, a frustrações e prejuízos. A identificação de cultivares mais adaptadas proporciona segurança aos agricultores, inclusive facilitando a obtenção de crédito e garantindo a aceitação do produto no mercado regional (Hamasaki et al., 1998).

O presente trabalho teve como objetivo estudar o desempenho agronômico de genótipos de pimenta-do-reino, em função da aplicação de doses crescentes de esterco bovino, nas condições edafoclimáticas do município de Areia, Paraíba.

\section{MATERIAL E MÉTODOS}

O trabalho foi desenvolvido em campo da UFPB, em Areia-PB, em área de Neossolo Regoliítico Psamítico típico. $\mathrm{O}$ delineamento experimental foi em blocos casualizados, com os tratamentos distribuídos no esquema fatorial $5 \mathrm{x}$ 3. Os fatores foram representados pelas

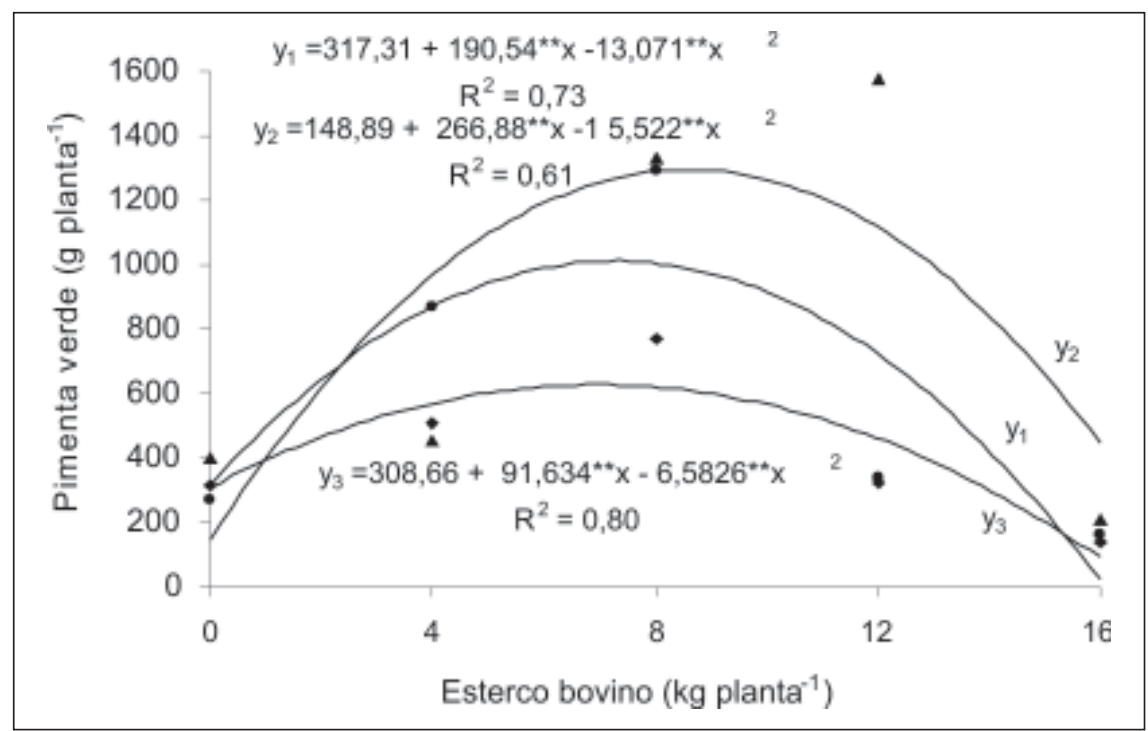

Figura 1. Produção em pimenta verde de três genótipos de pimenta-do-reino (Bragantina $\left(\mathrm{y}_{1}\right)$, Iaçará $\left(\mathrm{y}_{2}\right)$ e Cingapura $\left.\left(\mathrm{y}_{3}\right)\right)$, em função de doses crescentes da adubação com esterco bovino. (Yield of green pepper from tree black pepper genotypes (Bragantina $\left(\mathrm{y}_{1}\right)$, Iaçará $\left(\mathrm{y}_{2}\right)$ and Cingapura $\left(\mathrm{y}_{3}\right)$ ), submitted to levels of cattle manure). Areia, UFPB, 2006.

doses de esterco bovino (0; 4; 8; 12 e 16 kg planta-1) e pelos genótipos de pimenta-do-reino (Bragantina, Iaçará e Cingapura), adquiridos de viveirista credenciado pela Delegacia do Ministério da Agricultura do estado do Espiríto Santo, com quatro repetições por tratamentos. $\mathrm{O}$ solo apresentou as características: $\mathrm{pH} \mathrm{H}_{2} \mathrm{O}=7,0$; $\mathrm{P}$ disponível $=107,5 \mathrm{mg} \mathrm{dm}^{-3} ; \mathrm{K}^{+}$disponível = $64,0 \mathrm{mg} \mathrm{dm}{ }^{-3} ; \mathrm{Na}^{+}=0,09 \mathrm{cmol}_{\mathrm{c}} \mathrm{dm}^{-3}$, $\mathrm{H}^{+}+\mathrm{Al}^{+3}=0,91 \mathrm{cmol}_{\mathrm{c}} \mathrm{dm}^{-3}, \mathrm{Al}^{+3}=0,00$ $\mathrm{cmol}_{\mathrm{c}} \mathrm{dm}^{-3} ; \mathrm{Ca}^{+2}=2,70 \mathrm{cmol}_{\mathrm{c}} \mathrm{dm}^{-3} ; \mathrm{Mg}^{+2}$ $=0,75 \mathrm{cmol}^{\mathrm{c}} \mathrm{dm}^{-3}$. e matéria orgânica $=$ $12,5 \mathrm{~g} \mathrm{dm}^{-3}$. A caracterização química do esterco bovino revelou os teores em $\mathrm{g} \mathrm{kg}^{-1}$ de matéria seca: $\mathrm{P}=3,6 ; \mathrm{K}=4,1$; $\mathrm{N}=2,8$; matéria orgânica $=182 \mathrm{~g} \mathrm{dm}^{-3}$; e relação C/N = 10/1.

O preparo do solo constou de aração e gradagem, seguido da abertura das covas com 40 x 40 x $40 \mathrm{~cm}$. Foram utilizadas mudas com 40 dias de viveiro, transplantadas para covas distanciadas de $20 \mathrm{~cm}$ do tutor e protegidas com cobertura de palha. A parcela experimental foi composta por 30 plantas, espaçadas de 2,0 x 2,0 m, utilizando-se 15 plantas para avaliar a produção de pimenta verde e outras 15 para produção de pimenta seca.

Aplicou-se no plantio 50\% das doses estipuladas de esterco bovino acrescida de 50 g de superfosfato simples, 20 g de cloreto de potássio e 85 g de sulfato de amônio por cova. Seis meses após o transplantio, foi feita a primeira adubação de cobertura, com os 50\% restantes de esterco bovino, além de 70 g de sulfato de amônio, $16 \mathrm{~g}$ de superfosfato simples e 20 g de cloreto de potássio por planta. Aos 12 meses, realizou-se a segunda adubação suplementar, fornecendo-se os fertilizantes minerais referidos nas mesmas quantidades da cobertura anterior.

Os tratos culturais constaram de tutoramento com estacas de madeira da espécie Sabiá, com altura média de 2,0 m e diâmetro aproximado de $25 \mathrm{~cm}$; coroamento e amontoa para reduzir ervas espontâneas e riscos de excesso de água nas épocas chuvosas; capinas a enxada; amarrios para suplementar a fixação natural da planta ao tutor pelas raízes adventícias; poda, para eliminação de ramos axilares ("ladrões”); retirada das primeiras inflorescências, visando a proporcionar maior vigor da planta e colheitas mais elevadas nos anos subseqüentes; e irrigações, pelo sistema de aspersão, em períodos de estiagem.

As colheitas foram realizadas a partir da segunda floração no mês de março e entre novembro e dezembro de 2005. Para avaliação da produção de pimenta verde, as espigas foram colhi- 


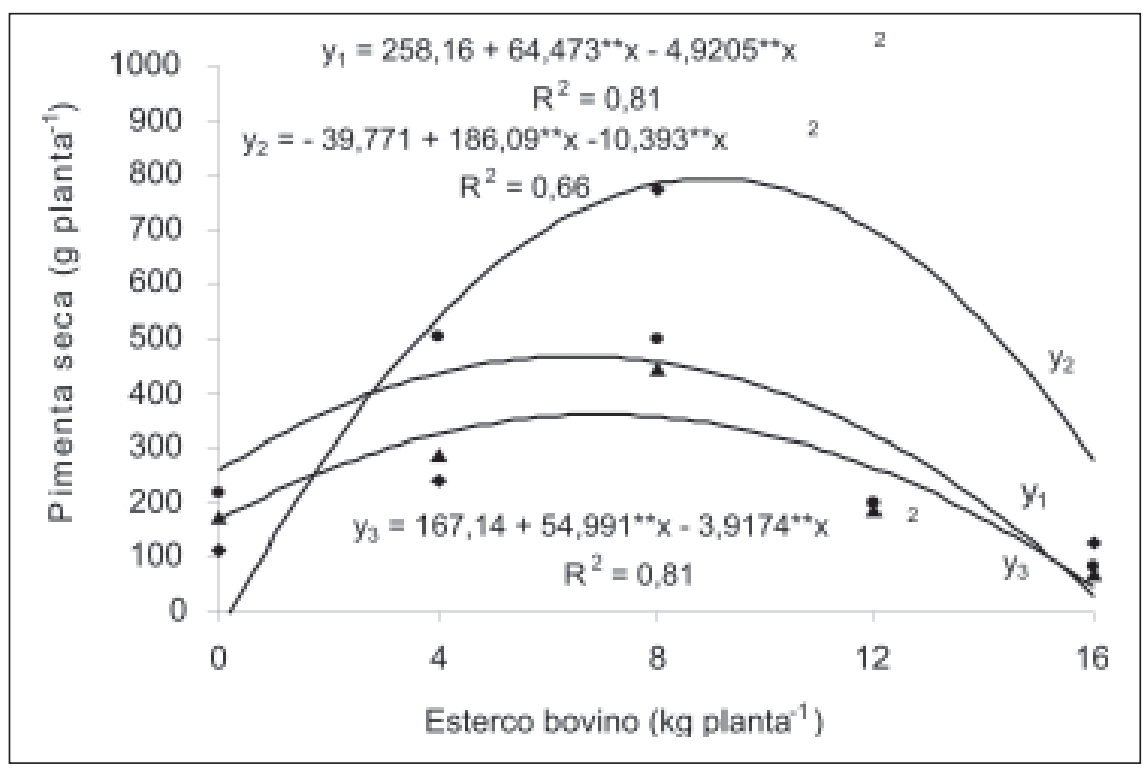

Figura 2. Produção em pimenta seca de três genótipos de pimenta-do-reino (Bragantina $\left(\mathrm{y}_{1}\right)$, Iaçará $\left(\mathrm{y}_{2}\right)$ e Cingapura $\left.\left(\mathrm{y}_{3}\right)\right)$, em função de doses crescentes da adubação com esterco bovino. (Yield of dry pepper of tree black pepper genotypes (Bragantina $\left(\mathrm{y}_{1}\right)$, Iaçará $\left(\mathrm{y}_{2}\right)$ and Cingapura $\left(\mathrm{y}_{3}\right)$ ), submitted to level of cattle manure). Areia, UFPB, 2006.

das quando as drupas atingiram, aproximadamente, 2/3 do máximo desenvolvimento. Para computar a produção em pimenta seca, as espigas foram colhidas com as drupas completamente desenvolvidas, apresentando coloração verde-clara, amarelada ou vermelha, sendo colocadas para secar ao sol (Duarte \& Albuquerque, 2005).

Os dados obtidos foram submetidos à análises de variância e de regressão, utilizando-se o teste F para comparação dos quadrados médios. Na análise de regressão, foram testados os modelos linear, quadrático e cúbico, sendo selecionado aquele capaz de melhor expressar cada característica avaliada, empregando-se o "software” SAEG (2000).

\section{RESULTADOS E DISCUSSÃO}

Houve efeito significativo $(\mathrm{p}<0,05)$ da interação entre genótipos de pimenta-do-reino e doses de esterco bovino, incluindo as médias relacionadas às produções de pimenta verde e seca por planta, ajustando-se ao modelo quadrático de regressão.

As máximas produções de pimenta vede por planta dos genótipos Bragantina (1012 g), Iaçará (1296 g) e Cingapura (627 g), foram obtidas com doses estimadas em 7,3; 8,6; e 7,0 kg planta-1 $^{-1}$ de esterco bovi- dos nutrientes (Peavy \& Greig, 1972). Corroborando essas conclusões, Pimentel (1985) relatou que a pimentado-reino necessita de adubos orgânicos para potencializar seu desempenho produtivo.

Dentro do programa de reativação da capacidade produtiva de áreas melhoradas e conseqüentemente, do agronegócio de pimenta-do-reino no estado da Paraíba, os genótipos Bragantina e Iaçara podem ser especialmente recomendados para as condições edafoclimáticas de Areia, empregandose o esterco bovino na adubação orgânica das lavouras.

\section{AGRADECIMENTEOS}

Os autores agradecem ao Banco do Nordeste do Brasil, pelo financiamento da pesquisa.

\section{REFERÊNCIAS}

no, respectivamente (Figura 1). Máxima produção de pimenta seca por planta foi obtida com doses estimadas em 6,5; 8,9; e 7,8 kg planta $^{-1}$ de esterco bovino, cujos valores corresponderam a 204, 793 e 358 g planta ${ }^{-1}$, respectivamente, para os genótipos Bragantina, Iaçará e Cingapura (Figura 2).

Os genótipos Bragantina e Cingapura requisitaram doses mais baixas de esterco bovino para atingir máximo potencial produtivo, porém, não conseguiram superar o genótipo Iaçará. Ainda, ficou evidente a correlação de comportamento para produções de pimenta verde e seca. Assim, os genótipos Bragantina e Cingapura apresentaram resultados idênticos para ambos os parâmetros de produção. No entanto, as colheitas foram inferiores àquelas registradas por Pimentel (1985) e por Duarte \& Albuquerque (2005), no estado do Pará, para esses mesmos genótipos.

Considerando em conjunto os dados obtidos, a pimenta-do-reino respondeu positivamente ao emprego de esterco bovino, nas condições edafoclimáticas do Brejo Paraibano, sendo recomendáveis doses variando de 6,0 a 8,0 kg plan$\mathrm{ta}^{-1}$ para possibilitar máximo potencial produtivo. Esse efeito, possivelmente decorreu de melhorias na estrutura do solo, resultando no aumento de trocas catiônicas (CTC) e no aproveitamento
DUARTE RML; ALBUQUERQUE CF. Dezembro 2005. Sistema de produção de pimentado-reino. Disponível em <http:// www.cpatu.embrapa.br/sistemasdeproducao. Acesso em 31 de março de 2006.

EMATER. 1979. Empresa de Assistência Técnica e Extensão Rural. 1979. Sugestões de adubações para o estado da Paraíba: primeira aproximação. João Pessoa, PB, 105 p.

FORNAZIER FILHO A. 1989. Pimenta-do-reino: uma das mais importantes especiarias do mundo. São Paulo: Ícone, 77 p.

GONDIM AWA. 1999. Geoeconomia e agricultura no Brejo Paraibano. João Pessoa: Editora Universitária. 209p.

HAMASAKI RI; BRAZ LT; PURQUERIO LFV; PEIXOTO N. 1998. Comportamento de novas cultivares de feijão-vagem em JaboticabalSP. CONGRESSO BRASILEIRO DE OLERICULTURA, 38, Petrolina. Resumo... Petrolina: SOB.

IBGE - Instituto Brasileiro de Geografia e Estatística. 2005. Levantamento sistemático da produção agrícola. João Pessoa.

MILANEZ D; VENTURA JA; FANTON CJ. 1987. Cultura da pimenta-do-reino. VitóriaES, EMCAPA, 94 p. (Documento, 33).

PEAVY WSE; GREIG JK. 1972. Organic and mineral fertilizers compared by yield, quality and composition of spinach. Journal American Society for Horticulture Science 97: 718-723.

PEIXOTO N; SILVA LO; THUNG MDT; SANTOS G. 1993. Produção de sementes de linhagens e cultivares arbustivas de feijão-vagem em Anápolis. Horticultura Brasileira 11: 151-152.

PIMENTEL AAMP. 1985. Olericultura no trópico úmido: hortaliças na Amazônia. São Paulo, Agronômica Ceres, 322 p.

SAEG. 2000. Sistema para análise estatística, versão 8.0. Viçosa-MG: Fundação Arthur Bernardes. 